\title{
Effects of Ageing on Bone Mineral Composition and Bone Strength
}

\author{
Raviraj Havaldar ${ }^{1}$, S. C. Pilli ${ }^{2}$, B. B. Putti ${ }^{3}$ \\ ${ }^{I}$ Assistant Professor, Department of Biomedical Engineering, KLESCET, Belgaum. \\ ${ }^{2}$ Principal, KLES College of Engineering and Technology, Belgaum. \\ ${ }^{3}$ Professor, Department of Orthopaedics, JNMC, KLE University, Belgaum
}

\begin{abstract}
With age in degenerative effects on the skeletal system there is increase in the risk of fracture. Mechanical strength of human bone depends on chemical constituents present in it. The present investigation focuses on estimation of bone inorganic constituents: calcium, phosphor and determination of mechanical strength: tensile, compression. Further a correlation is developed to establish relationship between mechanical strength and chemical composition. This study shows that bone mineral composition and ageing process are interdependent and are highly correlated. The mechanical behaviour of bone is characterised.
\end{abstract}

\section{Introduction:}

Bone materials are characterized by an astonishing variability and diversity. Their hierarchical organizations are often well suited and seemingly optimized to fulfil specific mechanical functions ${ }^{[1]}$. Mechanical testing is an important aspect of studying cortical bone mechanics. Bone is the primary load bearing constituent of the skeletal system. It serves several purposes in the body such as maintaining the shape of the body, in locomotion, protecting the soft tissues and supplying the frame work for bone marrow. The mineral content of bone serves as a reservoir for ions. According to the level of porosity and location within the skeleton, bone is categorized as either cortical bone or trabecular bone. At the ultra structural level, both cortical bone and trabecular bone are made up of bone tissue, which consists of approximately $65 \%$ mineral and $35 \%$ of organic matrix by mass. The mineral phase resembles hydroxyapatite crystals and the organic phase is primarily type I collagen. Cortical bone is relatively dense, with only microscopic channels. Cortical bone forms the outer wall of all bones and the diaphysis of long bones. It is largely responsible for the supportive and protective function of the skeleton. Almost $80 \%$ of the skeletal mass in the adult human skeleton is cortical bone, while the remaining $20 \%$ is trabecular bone ${ }^{[2,3]}$.

Profound changes in bone mineral compositions occur with aging ${ }^{[4]}$. Aging leads to the loss of bone mass which is associated with structural and metabolic deterioration ${ }^{[5]}$. The degree of bone mineralization is governed by hormonal, nutritional and mechanical factors. Generally, women have a lower bone mineral content than men, and this gap widens with increase in age. Additionally, women experience period of bone loss around the menopause. This accelerated loss is associated with the withdrawal of estrogen which begins at about age 40 years in both genders. Thus, in females and males, estrogen has both a catabolic and anabolic effect on bone throughout life, even at 80 to 90 years of age. In older men, osteoporosis is more closely related to low estrogen than to low androgen levels. The age related deterioration of the fracture properties of bone, coupled with higher life expectancy, is responsible for increasing incidence of bone fracture in elderly. This study focuses on how aging can alter the various mechanical properties of bone, and in particular the bone mineral composition and the strength associated with it. The fracture toughness of cortical bone show significant deterioration with aging ${ }^{[6]}$.

Burr and colleagues ${ }^{[7]}$ reviewed the potential role of skeletal microdamage in age-related fractures. They suggested that microdamage due to repetitive loading of bone is likely to initiate at the level of the collagen fiber and or may include mineral-collagen matrix, and also failure of the collagen fibber itself. The relationship between existing microcracks and bone mechanical properties has not been established in vivo, investigators have shown that damage accumulation in devitalized bone leads to a decrease in bone strength. Thus, the accumulation of microdamage in vivo may contribute to the increased fragility of the aging skeleton. An important aspect of bone tissue quality is the relative amount and the chemical properties of its main constituents, the organic matrix and the mineral crystals. The effect of mineralisation on mechanical properties of bone during ageing is investigated by Akkus et al ${ }^{[8]}$. Studies of the distribution of stress and strain within the organic and mineral components may illuminate the nanostructural origin of damage in bone. When bone is subjected to axial tensile stress, the organic matrix is subjected to both normal and shear stresses this may cause nanoscale damage in the organic matrix of bone ${ }^{[9]}$. Further delving into the hierarchical organisation of the organic matrix, which is made up of mainly type I collagen, acts as a composite material itself. The collagen fibrils transfer the tensile forces from one fibril to the next through shear stresses that are generated along the 
overlap region of the fibrils. Deformation of collagen fibres involves molecular stretching, slippage and ultimately defibrillation. These mechanisms decrease the fibril diameter and increase the toe region during subsequent tensile testing ${ }^{[10]}$.

In this investigation, studies are performed on human femur cortical bone. The estimation of inorganic chemical constituents namely, calcium and phosphorus is carried out by Atomic Absorption Spectrophotometer. Bone quality is a term associated with all indicators of fracture susceptibility such as bone mineral density, volume fraction, architecture, mineralisation and so on, which are dependent on age, gender, life style, food habits, place of living, economic factors etc. Characterization of the mechanical properties of bone is important for evaluation of bone pathologies, mechanical strength is analysed by using Instron 3366 table top model.

\section{Materials And Methods:}

Human femur cortical bone specimens are chosen as a source material used in our research work. It is believed that femur bone is the largest and longest among other long bones. Geometrically it is larger and rich in composition. Femur bone has high bone density and bone mass compared to other long bones of the body. Consequently specimen preparation is easier and greater ranges of the load capabilities of testing could be utilized.

Femur bones studied in this investigation are obtained in a fresh condition. Which are harvested from 55 donors who were non-diseased and non-hospitalised before death. The specimen samples included both the genders and are in the wide range of age groups of $19-83$ years. Test specimen preparation is begun immediately after obtaining the sample. The specimen samples are then embalmed and stored in a freezer to store at $-20^{\circ} \mathrm{C}$ wrapped in gauge soaked in phosphate buffered saline solution. Samples are tested with coded labelling to keep the patient information confidential. During all cutting and machining operations, the bone material is frequently and liberally sprayed with saline solution to maintain $\mathrm{pH}$ and to keep it wet. Two types of specimen in shape and dimension are prepared. For tensile test, dumbbell shape mechanical test specimens are obtained. For compression test, cylindrical specimens of equal diameter and height are prepared according to ADA specification.

Mechanical tests are performed on an Instron 3366 table top model Universal Testing Machine and the data is recorded at $50 \mathrm{~Hz}$. The range of the load cell for specimens is $2000 \mathrm{~N}$, with the resolution of $2.0 \mathrm{~N}$. the load cell applied to the specimen is measured directly by the load cell integral to the testing machine, the corresponding specimen deformation is determined by measuring the displacement of the moving cross-head of the testing machine. As the test specimens had a uniform cross-section, stress and strain were easily calculated from their original length and diameter measurements.

After specimens are examined for mechanical testings, the same specimens are digested using Aquaregia and analysed by Atomic Absorption Spectrophotometer model ELICO SL 168 India, for estimation of inorganic chemical constituents of femur cortical bone samples. The atomic absorption condition for Calcium is $422.7 \mathrm{~nm}$ and for Phosphorus it is $213.6 \mathrm{~nm}$. In this investigation the presence of calcium and phosphorus in femur cortical bone is quantified.

\section{Results:}

Fifty five samples are tested of various age groups ranging from 19 years to 83 years of both the genders. Age groups are divided into four categories; less than or equal to 30 years, in the range of $31-51$ years, $51-70$ years and above 70 years of age.

Table 1 shows the mechanical strength, table 2 shows the chemical analysis for all the specimens, table 3 shows the correlation of mechanical strength and chemical constituents.

Table 1 : Statistical analysis of bone mechanical strength for both male and female.

\begin{tabular}{|l|l|l|l|l|l|}
\hline Mechanical test & $\begin{array}{l}\leq 30 \text { years } \\
(13)\end{array}$ & $\begin{array}{l}31-50 \text { years } \\
(13)\end{array}$ & $\begin{array}{l}51-70 \text { years } \\
(15)\end{array}$ & $\begin{array}{l}>70 \text { years } \\
(14)\end{array}$ & P value \\
\hline $\begin{array}{l}\text { Tensile strength } \\
\text { MPa }\end{array}$ & $43.44 \pm 3.62$ & $39.82 \pm 4.29$ & $33.16 \pm 6.43$ & $30.16 \pm 7.09$ & $<0.001$ \\
\hline $\begin{array}{l}\text { Compressive } \\
\text { strength MPa }\end{array}$ & $155.8 \pm 9.53$ & $142.37 \pm 12.12$ & $124.44 \pm 15.40$ & $115.29 \pm 12.94$ & $<0.001$ \\
\hline
\end{tabular}

Table 2 : Statistical analysis of bone chemical composition for male and female.

\begin{tabular}{|l|l|l|l|l|l|}
\hline $\begin{array}{l}\text { Chemical } \\
\text { constituents }\end{array}$ & $\leq 30$ years (13) & $\begin{array}{l}31-50 \text { years } \\
(13)\end{array}$ & $\begin{array}{l}51-70 \text { years } \\
(15)\end{array}$ & $\begin{array}{l}>70 \quad \text { years } \\
(14)\end{array}$ & P value \\
\hline Calcium (\%) & $23.19 \pm 0.43$ & $22.43 \pm 0.98$ & $18.48 \pm 1.34$ & $15.51 \pm 1.35$ & $<0.001$ \\
\hline Phosphorus (\%) & $11.11 \pm 0.26$ & $10.89 \pm 0.38$ & $9.31 \pm 0.77$ & $8.01 \pm 0.75$ & $<0.001$ \\
\hline
\end{tabular}


Table 3 : Correlation analysis of Bone mechanical strength with chemical constituents for both genders.

\begin{tabular}{|l|l|l|}
\hline Mechanical strength & Calcium & Phosphorus \\
\hline Tensile strength & 0.962 & 0.952 \\
\hline Compressive strength & 0.935 & 0.921 \\
\hline P value & $<0.001$ & $<0.001$ \\
\hline
\end{tabular}

The normal, healthy calcified human femur bones showed a linear stress strain behaviour. Test specimen are of only healthy bone samples therefore specimens exhibited higher ultimate strain. The overall trend is towards higher toughness during both tensile and compressive tests. The mean tensile strength in males is $39.74 \pm 4.80 \mathrm{MPa}$ and in female it is $30.08 \pm 7.96 \mathrm{MPa}$. The mean compressive strength in males is found to be

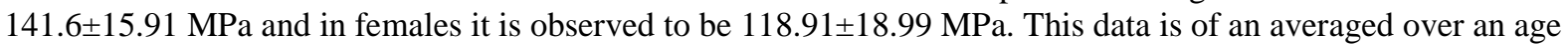
of $19-83$ years which includes both male and female. Age groups have been distinguished into 4 categories based on ageing, the young age as $\leq 30$ years, where 13 specimens are tested in this age group. The mean tensile strength is $43.44 \pm 3.62 \mathrm{MPa}$, the mean compressive strength is $155.87 \pm 9.53 \mathrm{MPa}$ with the mean calcium concentration of $23.19 \pm 0.43 \%$ and the mean phosphorus is $11.11 \pm 0.26 \%$. According to this study neither calcium nor phosphorus increased or decreased considerably between the age group of $19-30$ years. In the middle aged group 31-50 years, there are 13 specimens for testing which includes both male and female. The mean tensile strength is $39.82 \pm 4.29 \mathrm{MPa}$ and the mean compressive strength is $142.37 \pm 12.12 \mathrm{MPa}$. In comparison with the 19-30 years age group decrease in mechanical strength of both genders. The chemical constituents, the mean calcium concentration is $22.43 \pm 0.98 \%$ and phosphorus is $10.89 \pm 0.38 \%$. A considerable decrease is noticed in females than compared to males. In the upper middle age group $51-70$ years, the number of samples are of 14 specimens are tested consisting of both genders. The mean tensile strength is found to be $33.16 \pm 6.43 \mathrm{MPa}$ and the mean compressive strength is $124.44 \pm 15.40 \mathrm{MPa}$. This is due to after 50 years of age both male and female undergoes post menopausal period. Hence, bone looses protein structure leading to loose binding of minerals which results in reduced strength and also in chemical composition of calcium and phosphor. The mean calcium in this age group is $18.48 \pm 1.34 \%$ and the mean phosphorus is $9.31 \pm 0.77 \%$. In old aged group which is considered as $>70$ years, 14 specimens are tested which includes both male and females. During this age bone exhibits micro cracks, this causes microdamage in bones which in turn reduces the strength of the bone. The mean tensile strength is found to be $30.16 \pm 7.09 \mathrm{MPa}$ and the mean compressive strength is found to be $115.29 \pm 12.94 \mathrm{MPa}$, $(\mathrm{p}<0.001)$. In this age group there is huge loss of proteins and inorganic salts. It is also found that excretion of calcium and phosphorus increases as age advances hence the mean calcium present is $15.51 \pm 1.35 \%$ and the mean phosphorus is about $8.01 \pm 0.75 \%,(\mathrm{p}<0.001)$.

The correlation between mechanical strength and its chemical composition is summarised in table3, there exists the significance of high correlation of 0.962 between tensile strength and calcium $(\mathrm{p}<0.001)$, where as a correlation of 0.952 between compressive strength and calcium. Similarly the correlation factor between tensile strength and phosphorus is 0.935 where as for compressive strength and phosphorus is $0.921(\mathrm{p}<0.001)$. This suggests that tensile strength is highly dependent on calcium content of the bone.

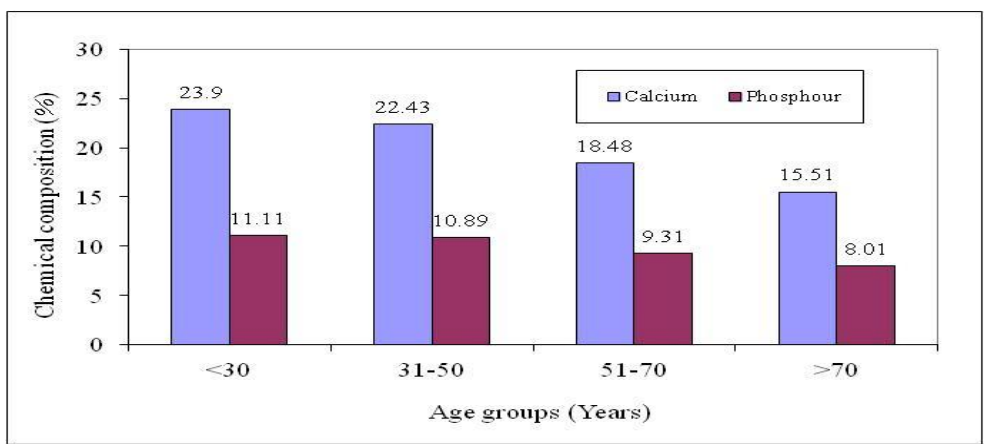

Fig.1. Average percentage of Calcium and Phosphorus of various age groups. Bone minerals are significantly greater in the age group of 30 years and below. There is no significant difference in calcium phosphor ratio for any of the age groups, ranging from 1.94 to 2.15 .

\section{Discussion :}

One of the most dramatic consequences of the aging of the human skeleton is the exponential increase in fracture incidence with age. The experimental procedures used to distribute the test specimen variables of human femur bones indicate the relationship between the age, gender and mechanical strength and chemical 
composition. As we did not observe any trend in fatigue property in the test specimens for any of the age group, this implies that the specimen storage conditions in this programme were successful in maintaining the compact bone material in a mechanically and chemically stabilized state over the wide range of age.

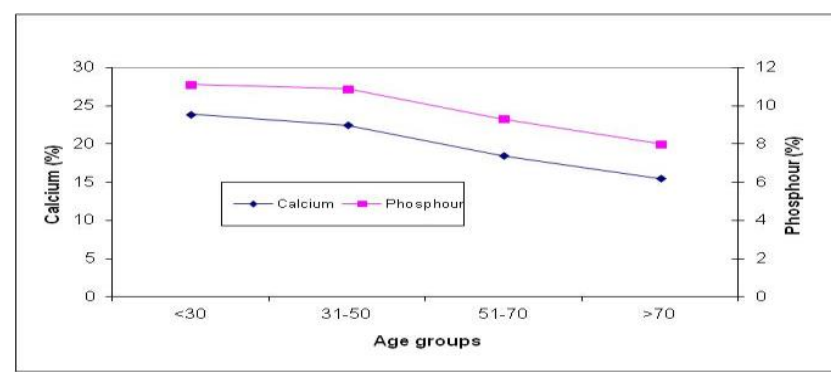

Fig. 2. Relationship between mean calcium, phosphorus and various age groups. There is a negative correlation between age and concentration of calcium, and phosphorus.

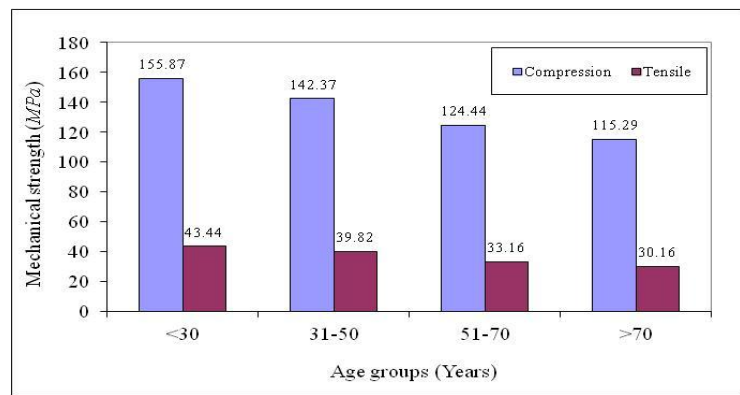

Fig. 3. Average mechanical strength of femur cortical bone of various age groups. Compression strength is greater than Tensile strength. Both strengths are significantly greater in the age group of 30 years, than any other age groups.

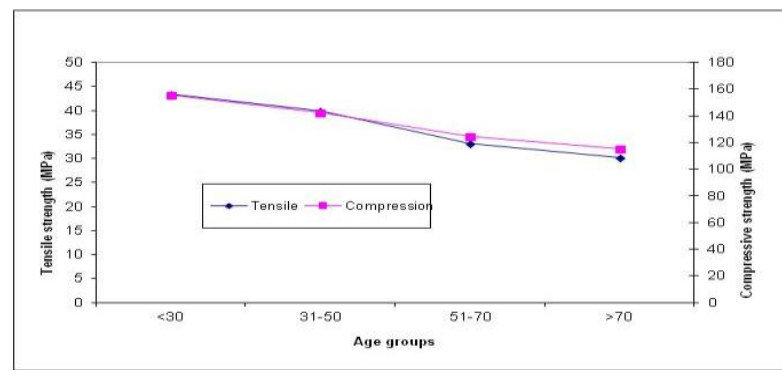

Fig. 4. Relationship between mean Tensile strength, Compressive strength and various age groups. There is a negative correlation between age and bone strength.

Ageing is known to increase non-enzymatic cross-linking in the collagen; as this reduces the post yield deformation of the collagen also has been used to explain the age-induced reduction in growth toughness ${ }^{[11]}$. Our results support the concept of reduced toughness with increase in age.

Age-related non-traumatic fractures are common occurrence and have been predicted with limited success by quantifying bone mass ${ }^{[12]}$. The present study suggests that investigations of bone quality in terms of its mineral constituents will provide successfully to predict and establish a biomechanical basis for the agerelated increase in the incidence of non-traumatic fractures. With respect to the role of ageing, the results show a definitive decrease in the bone mineral composition and the toughness implying that there is an increase in the porosity where interspace area increases with age, this indicates that there is extensive remodelling occurs in older bones to repair damage. Furthermore, based on the observations calcium and phosphor reduces in older age which leads to crack growth. When microcracks are initiated the bone becomes brittle therefore bone strength reduces drastically in the older age ${ }^{[13,14]}$.

It is believed that the degradation in crack bridging with age is the prominent effect responsible for the age-related deterioration in bone matrix toughness. It is also noted that ageing may result in many additional changes in the structure of bone at much smaller length scales. Thus with increase in age microdamage increases with lowered collagen quality and quantity ${ }^{[15,16]}$. This effect reduces elastic property, toughness of bone and increases non-traumatic fractures. 
On the basis of backscatter electron imaging, Crofts et al. ${ }^{[17]}$ found older cadavera $(60-71$ years old at death) to have a lower equivalent ash content in compact femur bone than younger cadaver (17 - 35 years old at death). Alternatively, Deng et al. ${ }^{[18]}$ found the geometric diameter up to the age of 35 which enhanced the bone mass and elastic modulus but in later stage of age groups both bone mass and elastic modulus decreased significantly therefore the study findings confirm those of Deng results. Ritchie et al. ${ }^{[19]}$ showed that from 20 to 80 years of age, ultimate stress, ultimate stiffness and failure energy of vertebral trabecular bone showed a linear decrease of $75 \%$ to $80 \%$ for vertical compression.

\section{Conclusion:}

The results of this study demonstrate that the age-related degradation in tissue level mechanical properties of human femoral cortical bone is significantly correlated with age-related changes in the chemical constituents of bone tissue. The fracture toughness of cortical bone shows significant deterioration with aging. Results demonstrate the need to interpret this deterioration in bone quality in terms of specific age groups and gender. The results show that bone mineral composition and ageing process are interdependent and highly correlated with mechanical of bone behaviour.

\section{References:}

[1] Fritsch A., and Hellmich C., Universal microstructural patterns in cortical and trabecular, extracellular and extravascular bone materials: Micromechanics-based prediction of anisotropic elasticity, J. of Theoretical Biology, vol. 244, pp. 597-620, 2007.

[2] Yerramshetty J. S., and Akkus O., The associations between mineral crystallinity and the mechanical properties of human cortical bone, J. Bone, vol. 42, pp. 476-482, 2008

[3] Heaney R. P., Phosphorus nutrition and the treatment of osteoporosis, J. of Mayo. Clin., vol. 79, pp. 91-97, 2004.

[4] Koester K. J., Barth H. D., and Ritchie R. O., Effect of aging on the transverse toughness of human cortical bone: Evaluation by R-curves, J. of Mechanical Behavior of Biomedical Materials, 2011

[5] Kruzic J. J., and Ritchie R. O., Fatigue of mineralized tissues: Cortical bone and dentin, J. of Mechanical Behavior of Biomedical Materials, vol. 1, pp. 3-17, 2008

[6] Fantner G. E., Rabinovych O., Schitter G., and Thurner P., Hierarchical interconnections in the nano-composite material bone: Fibrillar cross links resist fracture on several length scales, J. of Composites Science and Technology, vol. 66, pp. 1205-1211, 2006.

[7] D. B. Burr, Bone material properties and mineral matrix contributions to fracture risk or age in women and men, J. Musculoskel Neuron Interact, vol. 2, pp. 201-204, 2001.

[8] Akkus O., Adar F., and Schaffler M. B., Age-related changes in physicochemical properties of mineral crystals are related to impaired mechanical function of cortical bone, J. of Bone, vol. 34, pp. 443-453, 2004.

[9] Kotha S. P. and Guzelsu N., Modeling the tensile mechanical behaviour of bone along the longitudinal direction, J. Theor. Biol, vol. 219, pp. 269-279, 2002.

[10] Tomar V., Insights into the effects of tensile and copressive loadings on microstucture dependent fracture of trabecular bone, J. of Engineering Fracture Mechanics, 2009.

[11] Ritchie R. O., Nalla R. K., Kruzic J. J., and Ager J. W., Fracture and aging in bone: Toughness and structural charateristics, J. of Material Science, vol. 42, pp. 225-232, 2006

[12] George W. T. and Vashishth D., Susceptibility of aging human bone to mixed-mode fracture increases bone fragility, Bone, vol. 38 , pp. 105-111, 2006

[13] Kotha S. P. and Guzelsu N., Tensile damage and its effects on cortical bone, J. of Biomechanics, vol. 36, pp. 1683-1689, 2003.

[14] Vashishth D. and Sit S., Age-related changes in bending fatigue of human cortical bone, in 2003 summer Bioengineering Conference, Florida, 2003.

[15] Kinney J. H., Nalla R. K., Kruzic J. J., and Ritchie R. O., Effect of aging on the toughness of human cortical bone : Evaluation by R-curves, Bone, 2004

[16] Hoffler C. E., Moore K. E., and Kozloff K., Age, gender, and bone lamellae elastic moduli, J. of Orthopaedic Research, vol. 18, pp. 432-437, 2000.

[17] Crofts R. D., Boyce T. M., and Bloebaum R. D., Aging changes in osteeon mineralization in the human femoral neck, J. Bone, vol. 15 , pp. 147-152, 1994.

[18] H.-W. Deng, W.-M. Chen, and T. Conway, Determination of bone mineral density of the hip and spine in human pedegrees by genetic and life-style factors, Genetic Epidemiology, vol. 19, pp. 160-177, 2000.

[19] Ritchie R. O., Kinney J. H., Kruzic J. J., and Nalla R. K., Cortical bone fracture, in Wiley Encyclopedia of Biomedical Engineering, 2006. 